\section{Hypoxic training and team sports: a challenge to traditional methods?}

\author{
Grégoire P Millet, ${ }^{1}$ Raphaël Faiss, ${ }^{1}$ Franck Brocherie, ${ }^{1}$ Olivier Girard ${ }^{2}$
}

In 2007, Wilber ${ }^{1}$ presented the main altitude/hypoxic training methods used by elite athletes: 'live high-train high' (LHTH) and 'live high-train low' (LHTL); sleeping at altitude to gain the haematological adaptations (increased erythrocyte volume) but training at sea level to maximise performance (maintenance of sea-level training intensity and oxygen flux). The LHTL method can be accomplished through a number of methods and devices: natural/ terrestrial altitude, nitrogen dilution, oxygen filtration and supplemental oxygen. Another method is the live low-train high' (LLTH) method including intermittent hypoxic exposure at rest (IHE) or during intermittent hypoxic training sessions (IHT). Noteworthy, all supporting references were conducted with endurance elite athletes (ie, cyclists, triathletes, crosscountry skiers, runners, swimmers, kayakers and rowers) and there is an extensive literature relative to LHTH as well as LHTL. However, there is a lack of evidence for the applicability of these methods in team-sport athletes.

In recent times, media reports have provided us with coverage of some highprofile clubs or national squads in various team-sport disciplines undertaking fitness programmes at altitude during the early preseason or in preparation of a major competition. Despite the evident observation that athletes from different team sports and from all around the world are using altitude training more than ever before, it is stunning to note that to date there are only two hypoxic training studies that have been conducted with team-sport players. $^{2} 3$ Therefore, there is an urgent need for mechanistic as well as applied studies investigating team-sport performance changes following hypoxic training in a sport-specific population

\footnotetext{
${ }^{1}$ Faculty of Biology and Medicine, Department of Physiology, Institute of Sports Sciences, University of Lausanne, Lausanne, Switzerland; ' $A$ ASPETAR, Qatar Orthopaedic and Sports Medicine Hospital, Doha, Qatar

Correspondence to Professor Millet, Department of Physiology, Faculty of Biology and Medicine, Institute of Sports Sciences, University of Lausanne, Géopolis, Quartier Mouline, Lausanne 1015, Switzerland; gregoire.millet@unil.ch
}

before solid evidence-based recommendations can be definitely formulated.

In parallel, over the last few years, an increasing interest for the practical application of altitude training in team sports - mainly in football but also in the rugby union or the Australian football leaguewas noted due to several reasons. First, there were controversies regarding the possibility of playing international football matches above $2500 \mathrm{~m}$ in the mountainous regions of South America, while guaranteeing players health and safety. Second, the FIFA 2010 Senior (South Africa) and 2011 U-20 (Columbia) World Cups held at altitude have highlighted the need for the squads to achieve optimal acclimatisation. Third, the development of new hypoxic devices (eg, mobile inflatable hypoxic marquees) and methods (repeated sprints in hypoxia). This increased interest was translated by the organisation of international symposia on the topic by the leading sports organisation; for example, FIFA, symposium on playing football at altitude ${ }^{4}$; International Olympic Committee, consensus statement on thermoregulatory and altitude challenges for all high-level athletes. ${ }^{5}$ In March 2013, Aspetar Hospital invited several top international experts in the field of altitude training to establish a forum of research and clinical insights for the practical application of altitude training with team-sport players.

The intrinsic differences between factors underlying endurance (eg, maximal aerobic speed, economy) and team-sport performance (eg, repeated-sprint ability) as well as the constraints in the respective competition calendars explain why the aims and contents of the hypoxic methods and their periodisation in the yearly programme are largely different between individual and team sports. As such, we believe that the current nomenclature is probably not appropriate anymore for exploring the new boundaries of contemporary hypoxic methods offered to team-sport athletes. In 2010, we $^{6}$ therefore proposed to slightly modify Wilber's nomenclature by introducing the possibility of combining different hypoxic methods. New approaches include
'IHE during interval-training' (IHIT = IHT + IHE) and 'live high-train low and high $\quad(\mathrm{LHTLH}=\mathrm{LHTL}+\mathrm{IHT})$. Since more information became available on enhanced glycolysis and buffering capacity with $\mathrm{IHT}^{7}$ we discussed also the potential benefits of these hypoxic methods for anaerobic performance.

Unfortunately there is to date no expert consensus on how we should name the different hypoxic methods. ${ }^{6}$ IHT that should refer to interval training in hypoxia ${ }^{8}$ is also used for continuous lowintensity $\left(<70 \% \quad \mathrm{VO}_{2 \max }\right)$ long duration (>30 min) exercise in hypoxia. ${ }^{9}$ Recently, we also proposed a new hypoxic method (RSH, repeated sprint training in hypoxia) presumably based on different mechanisms than IHT. ${ }^{10}$ It is beyond the scope of this editorial to review the mechanisms underpinning these three subcategories of LLTH but, in our view, the time has come to update the current nomenclature since each method is likely based predominantly on different mechanisms; for example, increased oxidative capacity (CHT), buffering capacity (IHT) or compensatory fiber-selective vasodilation (RSH). Our suggestion is therefore to divide the LLTH method in four subsets; that is, IHE, CHT (continuous $>30 \mathrm{~min}$ low intensity training in hypoxia), IHT (interval-training in hypoxia) and $\mathrm{RSH}$ (figure 1). Another point that deserves attention is the nature of altitude stress. If Wilber distinguished 'natural/terrestrial' and 'simulated' LHTL methods in his classification, such differentiation was absent for the LLTH methods. With mounting evidence suggesting that hypobaric hypoxia induces different physiological adaptations than normobaric hypoxia, ${ }^{11}$ we therefore believe that it is paramount to systematically report the method lowering ambient oxygen partial pressure.

Pending confirmatory research, we propose that not just one but a combination of various methods targeting different attributes of team-sport athletes over the course of the yearly plan would be more beneficial. It is our hope that the possibility of combining various hypoxic training methods-as described in this editorial-would open unexplored research avenues (eg, preacclimatisation, maintenance of the gains following an altitude sojourn, accelerating return to play for injured players and/or preventing detraining during the off-season) supporting best practice of team-sport athletes. 


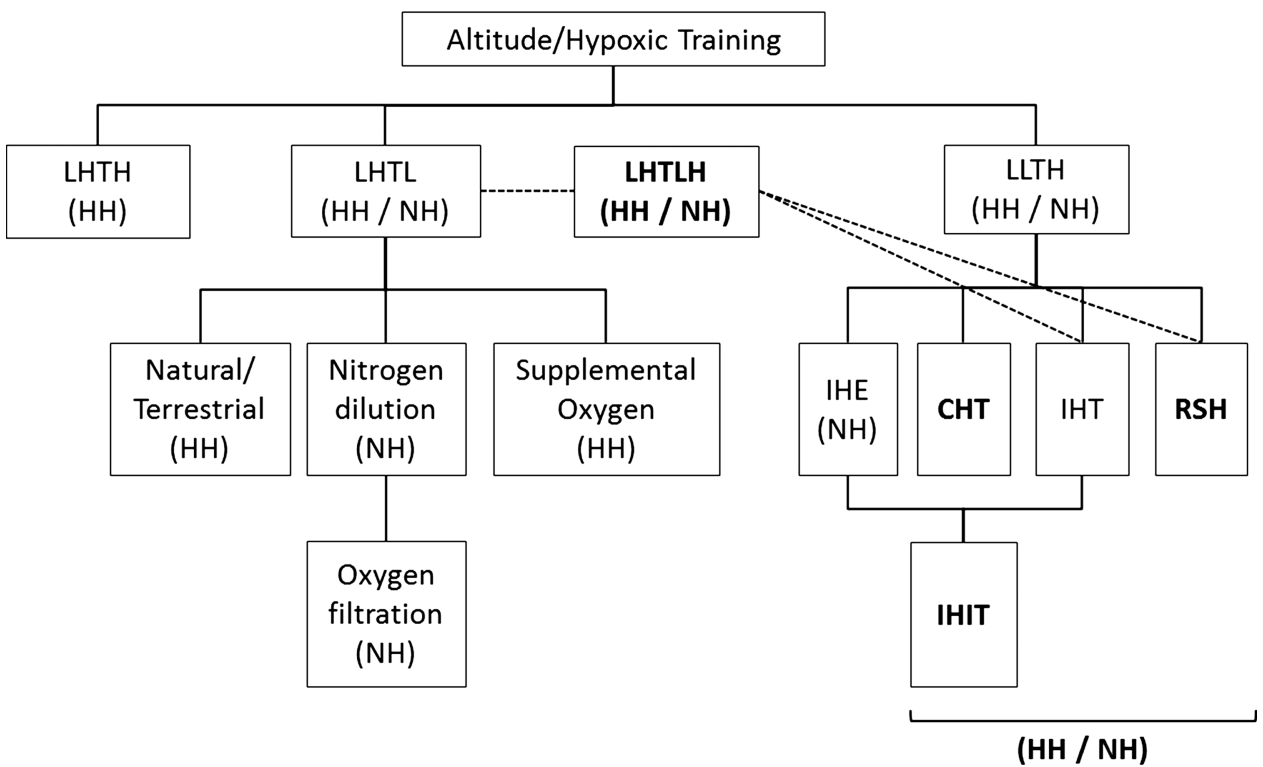

Figure 1 Updated panorama of the different hypoxic methods currently available for a range of athletes engaged in endurance and team-sport disciplines. Adapted from Wilber ${ }^{1}$ and Millet et al ${ }^{6}$ with proposed changes highlighted in bold. LHTH, live high-train high; LHTL, live high-train low; LHTLH, live high-train low and high; LLTH, live low-train high; IHE, intermittent hypoxic exposure; CHT, continuous hypoxic training; IHT, interval hypoxic training; RSH, repeated sprint training in hypoxia; IHIT, IHE during interval-training; $\mathrm{NH}$, normobaric hypoxia; HH, hypobaric hypoxia.

Competing interests None.

Provenance and peer review Not commissioned; externally peer reviewed.

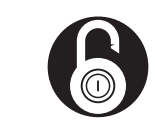

\section{OPEN ACCESS}

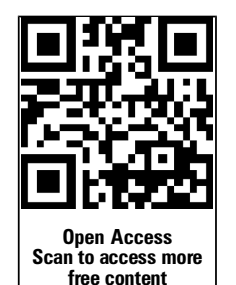

Open Access This is an Open Access article distributed in accordance with the Creative Commons Attribution Non Commercial (CC BY-NC 3.0) license, which permits others to distribute, remix, adapt, build upon this work non-commercially, and license their derivative works on different terms, provided the original work is properly cited and the use is non-commercial. See: http://creativecommons.org/ licenses/by-nc/3.0/

To cite Millet GP, Faiss $R$, Brocherie $F$, et al. $B r$ J Sports Med 2013;47:i6-i7.

Accepted 10 September 2013

Br J Sports Med 2013;47:i6-i7.

doi:10.1136/bjsports-2013-092793

\section{REFERENCES}

1 Wilber RL. Application of altitude/hypoxic training by elite athletes. Med Sci Sports Exerc 2007;39:1610-24.

2 Morton JP, Cable NT. Effects of intermittent hypoxic training on aerobic and anaerobic performance. Ergonomics 2005:48:1535-46.

3 Hamlin MJ, Hinckson EA, Wood MR, et al. Simulated rugby performance at 1550-m altitude following adaptation to intermittent normobaric hypoxia. J Sci Med Sport 2008;11:593-9.

4 Bartsch P, Saltin B, Dvorak J. Consensus statement on playing football at different altitude. Scand J Med Sci Sports 2008:18:96-9.

5 Bergeron MF, Bahr $R$, Bartsch $P$, et al. International Olympic Committee consensus statement on thermoregulatory and altitude challenges for high-level athletes. Br J Sports Med 2012;46:770-9.

6 Millet GP, Roels B, Schmitt L, et al. Combining hypoxic methods for peak performance. Sports Med 2010;40:1-25

7 Gore CJ, Clark SA, Saunders PU. Non-hematological mechanisms of improved sea-level performance after hypoxic exposure. Med Sci Sports Exerc 2007;39:1600-9.

8 Roels B, Bentley DJ, Coste 0 , et al. Effects of intermittent hypoxic training on cycling performance in well-trained athletes. Eur J Appl Physiol 2007:101:359-68.

9 Terrados N, Jansson E, Sylven C, et al. Is hypoxia a stimulus for synthesis of oxidative enzymes and myoglobin? J Appl Physiol 1990;68: 2369-72.

10 Faiss $\mathrm{R}$, Leger $\mathrm{B}$, Vesin JM, et al. Significant molecular and systemic adaptations after repeated sprint training in hypoxia. PLOS ONE 2013;8: e56522.

11 Millet GP, Faiss R, Pialoux V. Point: hypobaric hypoxia induces different physiological responses from normobaric hypoxia. J Appl Physiol 2012;112:1783-4. 